\title{
Effects of Temperature on the Atomic Structure of Synthetic Calcium- Silicate-Deuterate Gels: A Neutron Pair Distribution Function Investigation
}

\author{
Claire E. White ${ }^{1}$ \\ ${ }^{1}$ Department of Civil \& Environmental Engineering and Andlinger Center for Energy and the \\ Environment, Princeton University, Princeton, USA \\ * Corresponding author: Phone: +1 609258 6263, Fax: +1 609258 2799, Email: \\ whitece@princeton.edu \\ Postal address: Department of Civil \& Environmental Engineering, E-Quad, Princeton \\ University, Princeton NJ 08544, USA
}

\section{Keywords}

Calcium-Silicate-Hydrate (C-S-H); Characterization; Stability; Temperature; Neutron Pair Distribution Function

\begin{abstract}
Due to the nanocrystallinity of the calcium-silicate-hydrate $(\mathrm{C}-\mathrm{S}-\mathrm{H})$ gel in ordinary Portland cement-based paste combined with the presence of nanoscale heterogeneities such as varying calcium-to-silicon ratio and incorporation of aluminum in the structure, standard characterization techniques fail to fully capture the complex atomic structure and nanoscale morphology of this important binder phase. Here, neutron pair distribution function (PDF) analysis is applied to a range of deuterated $\mathrm{C}-\mathrm{S}-\mathrm{H}$ gels with varying $\mathrm{Ca} / \mathrm{Si}$ ratios (denoted $\mathrm{C}-\mathrm{S}-\mathrm{D}$ ). In situ temperature
\end{abstract}


measurements reveal that the local atomic bonding environments in C-S-D gel undergo large structural rearrangements due to exposure to elevated temperature (above $\sim 200{ }^{\circ} \mathrm{C}$ ), including the collapse of the C-S-D gel interlayer spacing to $9.6 \AA$ and the emergence of a dicalcium silicate phase (similar to larnite). At lower elevated temperatures, the atom-atom correlations are dominated by scattering from deuterium atoms and therefore can be used to quantify the dehydration kinetics.

\section{Introduction}

Ordinary Portland cement (OPC)-based concrete has been used in the construction industry for more than 175 years; however, the main phase that controls strength and durability, calciumsilicate-hydrate (C-S-H) gel, is still being actively characterized at the atomic length scale [1]. This is due to the fact that C-S-H gel co-exists with multiple other phases in OPC concrete, including portlandite, ettringite and various other sulfates phases, which makes isolation of the gel extremely difficult. Current investigations on C-S-H gel tend to revolve around synthetic versions, such as the double-decomposition method [2] and synthesis from tricalcium silicate $\left(\mathrm{C}_{3} \mathrm{~S}\right)$ and amorphous silica [3]. These synthetic synthesis routes enable new information to be obtained on C-S-H gel, with the caveat that these gels may differ in structure and stability from the natural C-S-H gel existing in OPC concrete. Nevertheless, with recent advances in experimental characterization techniques, including pair distribution function (PDF) analysis, which consists of Fourier transforming high-resolution (and high- $Q$ space) diffraction data, important new information on the atomic structure of synthetic C-S-H gels has been recently obtained [2,3]. 
The atomic structure of $\mathrm{C}-\mathrm{S}-\mathrm{H}$ gel has been the topic of recent debate in the literature, with new structural models generated using quantum chemistry being presented in the community [4,5]. Experimentally-driven structural representations have been developed using techniques such as reverse Monte Carlo [2], with additional research required to fully-validate these models from a thermodynamics viewpoint to ensure that the models are chemically-reasonable. The X-ray PDF experimental data reported by Skinner et al. [2] revealed that the atomic structure of a synthetic C$\mathrm{S}-\mathrm{H}$ gel (synthesized using $\mathrm{CaO}$ and $\mathrm{SiO}_{2}$ ) was nanocrystalline and possessed atom-atom correlations up to $\sim 40 \AA$. We recently confirmed this structural coherence length using X-ray PDF analysis of deuterated C-S-H (C-S-D) gels synthesized from $\mathrm{C}_{3} \mathrm{~S}$ and amorphous silica [3], which is in agreement with the transmission electron microscopy (TEM) results from Richardson [6]. At the smaller length scale, the local bonding environments in $\mathrm{C}-\mathrm{S}-\mathrm{H}$ gels have been investigated using nuclear magnetic resonance, Raman and infrared spectroscopy [1,7-9], and it is well-known that the structure of C-S-H gel consists of a defect dreierketten silicate chain structure, which varies in length according to the $\mathrm{Ca} / \mathrm{Si}$ ratio [10].

Although the structure of C-S-H gel has been investigated extensively in recent decades, little information is available regarding the atomic structural changes that occur when the gel is exposed to elevated temperatures. These changes are extremely important for understanding how OPC concrete performs at high temperatures, especially in fire conditions [11,12]. Furthermore, moderate temperatures $\left(\sim 100{ }^{\circ} \mathrm{C}\right)$ are routinely used in sample preparation for experimental characterization methods such as nitrogen sorption and mercury intrusion porosimetry, where water in pores must be removed. It is known that oven drying at these temperatures $\left(\sim 100{ }^{\circ} \mathrm{C}\right)$ leads to a build-up in capillary pore pressures and associated stresses, which leads to cracking and 
damage to the pore structure [13]. The local bonding environment around the silicon atoms has been seen to change when exposed to these moderate temperatures $\left(110^{\circ} \mathrm{C}\right)[14]$. However, the extent of change in the medium range ordering of the atomic structure of C-S-H gel in response to these moderate and high temperatures is not well understood, primarily due to the disordered nature of the gel at this length scale.

Progress has been made by investigating the structural changes occurring to calcium silicate minerals such as $11 \AA$ A tobermorite (a crystalline analogue for C-S-H gel), which has been seen to decrease in interlayer spacing from 11.3 to $9.3 \AA$ 践 when heated to $300{ }^{\circ} \mathrm{C}$ (and remains intact with the interlayer spacing at $9.3 \AA$ past $700{ }^{\circ} \mathrm{C}$ ) [15]. Other specimens of $11 \AA$ tobermorite, known as anomalous tobermorite, retain an interlayer spacing of $11.3 \AA$ up to $700-800{ }^{\circ} \mathrm{C}$, although they still lose the interlayer water (as measuring using thermogravimetric analysis) [15]. The presence of decreased interlayer spacings (along the $c$ axis of the unit cell) at elevated temperatures has also been seen for $14 \AA$ tobermorite, where a broad $9.6 \AA$ spacing appears at temperatures above $\sim 300$ ${ }^{\circ} \mathrm{C}$ [16]. The thermal behavior of C-S-H gel in OPC paste has been investigated using neutron diffraction [17]; however, due to the existence of multiple phases in the sample, the exact behavior of the C-S-H gel remains unclear. The neutron investigation revealed that the Bragg peak assigned to $\mathrm{C}-\mathrm{S}-\mathrm{H}$ gel completely disappeared by $400^{\circ} \mathrm{C}$, and that the decomposed $\mathrm{C}-\mathrm{S}-\mathrm{H}$ contributed to the formation of calcite and larnite. However, there was no mention of changes occurring in the interlayer spacing of C-S-H gel due to temperature, and the main peak of C-S-H gel (at a $Q$ spacing of $2.08 \AA^{-1}$ using neutrons) was labelled as larnite and/or portlandite. 
Here, neutron total scattering measurements and subsequent PDF analysis is used to investigate the atomic structure of C-S-D gels together with the structural changes that occur due to dehydration and exposure to high temperatures (up to $650^{\circ} \mathrm{C}$ ). By using the high-flux available at recently built spallation sources, it is possible to study the dehydration and high temperature reactions in situ using neutrons, and therefore obtain information on the exact local structural changes that occur to the deuterium-containing correlations during exposure to these elevated temperature.

\section{Materials and Methods}

C-S-D gels of varying $\mathrm{Ca} / \mathrm{Si}$ ratios $(0.57,0.93,1.15,1.32$ and 1.42$)$ were synthesized using triclinic tricalcium silicate $\left(\mathrm{C}_{3} \mathrm{~S}\right.$, CTLGroup) and amorphous fumed silica $\left(\mathrm{SiO}_{2}\right.$, Alfa Aesar, 325 mesh) with the overall $\mathrm{Ca} / \mathrm{Si}$ ratio of the samples being $0.83,1.2,1.5,1.7,3.0$. The discrepancy between the gel and sample $\mathrm{Ca} / \mathrm{Si}$ ratio is due to the presence of unreacted $\mathrm{C}_{3} \mathrm{~S}$ and portlandite. The synthesis method used to produce these samples was previously outlined in detail in reference [3], together with determination of the $\mathrm{Ca} / \mathrm{Si}$ ratio of the gels. Briefly, the given amounts of $\mathrm{C}_{3} \mathrm{~S}$ and fumed silica were sonicated in acetone to produce a homogenous powder with the specified $\mathrm{Ca} / \mathrm{Si}$ ratio. After the powders were rigorously dried for $12 \mathrm{hrs}$ to remove all the acetone using a vacuum oven set at $40{ }^{\circ} \mathrm{C}$, they were hydrated using $\mathrm{D}_{2} \mathrm{O}$ (Sigma-Aldrich, 99.9\%), sealed in plastic containers and left to cure for 1 month under ambient laboratory temperature conditions. Immediately prior to the neutron scattering experiments the samples were crushed using a mortar and pestle and loaded into standard vanadium cans ( $3 / 8$ inch inner diameter) in an inert environment (helium). Preliminary neutron measurements revealed that the samples had an extremely high water content, so the additional amounts of each powder were placed in a vacuum 
chamber and exposed to vacuum for $2 \mathrm{hrs}$ at $40{ }^{\circ} \mathrm{C}$ to remove excess water. Vanadium cans were not sealed with indium wire to ensure vapor loss was possible during the high temperature measurements.

The samples were measured on the Nanoscale-Ordered Materials Diffractometer (NOMAD) instrument at the Spallation Neutron Source, Oak Ridge National Laboratory [18]. Ambient temperature measurements of the C-S-D gels were obtained on the samples loaded in vanadium cans using the sample changer. Each sample was measured for $45 \mathrm{~min}$. In situ drying measurements of the C-S-D gel with a $\mathrm{Ca} / \mathrm{Si}$ ratio of 1.32 were obtained using an argon Cobra Cryostream sample environment and a set point of $110^{\circ} \mathrm{C}$. Data sets were collected every $15 \mathrm{~min}$ for a duration of $5.5 \mathrm{hrs}$. Data sets have been labelled according to the extent of time the sample was subjected to, and the time given is at the end of the most recent 15 min acquisition. For instance, the $5.5 \mathrm{hr}$ data set is $15 \mathrm{~min}$ measurement of the sample that commenced at $5.25 \mathrm{hr}$ at $110{ }^{\circ} \mathrm{C}$ and finished at $5.5 \mathrm{hr}$. In situ dehydration/decomposition measurements of the C-S-D gel with a $\mathrm{Ca} / \mathrm{Si}$ ratio of 0.57 (ratio of 0.83 for the sample) were obtained using the ILL furnace available on the NOMAD instrument. The sample was heated at a ramp rate of $2{ }^{\circ} \mathrm{C} / \mathrm{min}$ with $3 \mathrm{hr}$ soak times at $110,250,450$ and $650{ }^{\circ} \mathrm{C}$. Measurements were obtained every 15 min throughout the temperature run. Due to lower signal/noise present in the data at higher temperature $(>230$ $\left.{ }^{\circ} \mathrm{C}\right)$, together with more gradual changes in the local atomic structure at these higher temperatures, data sets have been merged above $230{ }^{\circ} \mathrm{C}$ to enhance the signal/noise. For the 250,450 and 650 ${ }^{\circ} \mathrm{C}$ soak times, all twelve (ten for the case of $650{ }^{\circ} \mathrm{C}$ ) 15 min scans have been merged for each given temperature. For non-soak temperature scans, the reported temperature is the middle point of the temperature range (e.g., $95^{\circ} \mathrm{C}$ is the data set acquired when the furnace was ramping from 
80 to $110^{\circ} \mathrm{C}$ ). For the soak temperature of $110^{\circ} \mathrm{C}$, the data sets were not merged, and the reported times for these data sets follow the same nomenclature as that used for the in situ drying measurement of the C-S-D gel with $\mathrm{Ca} / \mathrm{Si}$ ratio of 1.32 .

To produce each total scattering function and associated PDF, the measured scattered intensities were normalized by scattering from a vanadium rod and then subjected to a background subtraction from the empty container using the IDL software developed for the NOMAD instrument. Prior to calculation of the PDF, the total scattering function was multiplied by a Lorch function [19] to improve the signal/noise at the expense of real-space resolution. The PDF, $G(r)$, was obtained via a sine Fourier transform of the total scattering function, $S(Q)$, using a $Q_{\max }$ of $20 \AA^{-1}$,

$$
G(r)=\frac{2}{\pi} \int_{Q=Q_{\min }}^{Q=Q_{\max }} Q[S(Q)-1] \sin (Q r) d Q
$$

where $Q$ is the momentum transfer defined as

$$
Q=\frac{4 \pi \sin \theta}{\lambda}
$$

To assess the water content of the samples after vacuum drying, thermogravimetric analysis was performed using a Perkin-Elmer Pyris 1 TGA. Samples were loaded into platinum pans and heated from 30 to $350{ }^{\circ} \mathrm{C}$ at a rate of $20{ }^{\circ} \mathrm{C} / \mathrm{min}$ in a nitrogen atmosphere. These measurements were conducted on the samples two years after synthesis and therefore addition hydration (and potential carbonation) will have occurred. 
The unreacted amorphous fumed silica content in the powders was analyzed using attenuated total reflectance (ATR) Fourier transform infrared spectroscopy (FTIR). The instrument (Perkin-Elmer Frontier MIR with a Frontier UATR diamond/ZnSe attachment) was purged with nitrogen to remove atmospheric carbon dioxide and water molecules prior to measurement. Transmission spectra were collected from 4000 to $450 \mathrm{~cm}^{-1}$ at a resolution of $4 \mathrm{~cm}^{-1}$ and an accumulation of 16 scans. The amorphous fumed silica source measured using ATR-FTIR was from Alfa Aesar (surface area of $300-350 \mathrm{~m}^{2} / \mathrm{g}$ ). As was the case for the TGA measurements, the FTIR analysis was carried out two years after synthesis of the samples.

\section{Results and Discussion}

\section{Atomic Ordering at Ambient Temperature}

Figure 1 displays the neutron scattering data of the C-S-D gels, where Figure 1a provides the total scattering functions of the gels (in reciprocal space) and Figure 1b the neutron PDFs. As was the case for the X-ray data in our previous investigation [3], it is clear that for increasing $\mathrm{Ca} / \mathrm{Si}$ ratio the amount of portlandite dramatically increases. However, the $\mathrm{C}_{3} \mathrm{~S}$ peaks remain relatively small irrespective of the $\mathrm{Ca} / \mathrm{Si}$ ratio, which is attributed to the smaller neutron coherent scattering length of silicon and calcium compared to oxygen and deuterium. Therefore, as portlandite precipitation increases (as the $\mathrm{Ca} / \mathrm{Si}$ ratio increases), and an increasing fraction of deuteroxyl (OD) units are associated with this crystal structure, the Bragg peaks associated with this crystalline phase are also seen to increase significantly. A qualitative analysis of Figure 1a reveals that portlandite is present in the samples with $\mathrm{Ca} / \mathrm{Si}$ ratios of 1.7 and 3 . Figure 1 a also contains information on the amount of water present in the sample in the form of $\mathrm{D}_{2} \mathrm{O}$ or deuteroxyl units via the broad 
amorphous peak situated between 1 and $3.5 \AA^{-1}$ [20]. It is seen that this peak is most dominant for the gel with a $\mathrm{Ca} / \mathrm{Si}$ ratio of 0.57 (ratio of 0.83 for the sample), and diminishes in size as the $\mathrm{Ca} / \mathrm{Si}$ ratio increases. This implies that the lower $\mathrm{Ca} / \mathrm{Si}$ ratio gels contain more water, which is in agreement with the synthesis method, where high water/precursor ratios were required for the systems containing more silica (lower $\mathrm{Ca} / \mathrm{Si}$ ratios) due to the high surface area of the silica source [3]. Subsequent drying of the samples prior to the neutron experiments does not lead to an equal amount of water being present in these samples. However, as seen in the Supplementary Material, the water content of the gels is relatively similar after two years of hydration, as measured using thermogravimetric analysis, which is potentially due to the effects of additional hydration and carbonation, even though the samples were sealed in an inert environment.

(a)

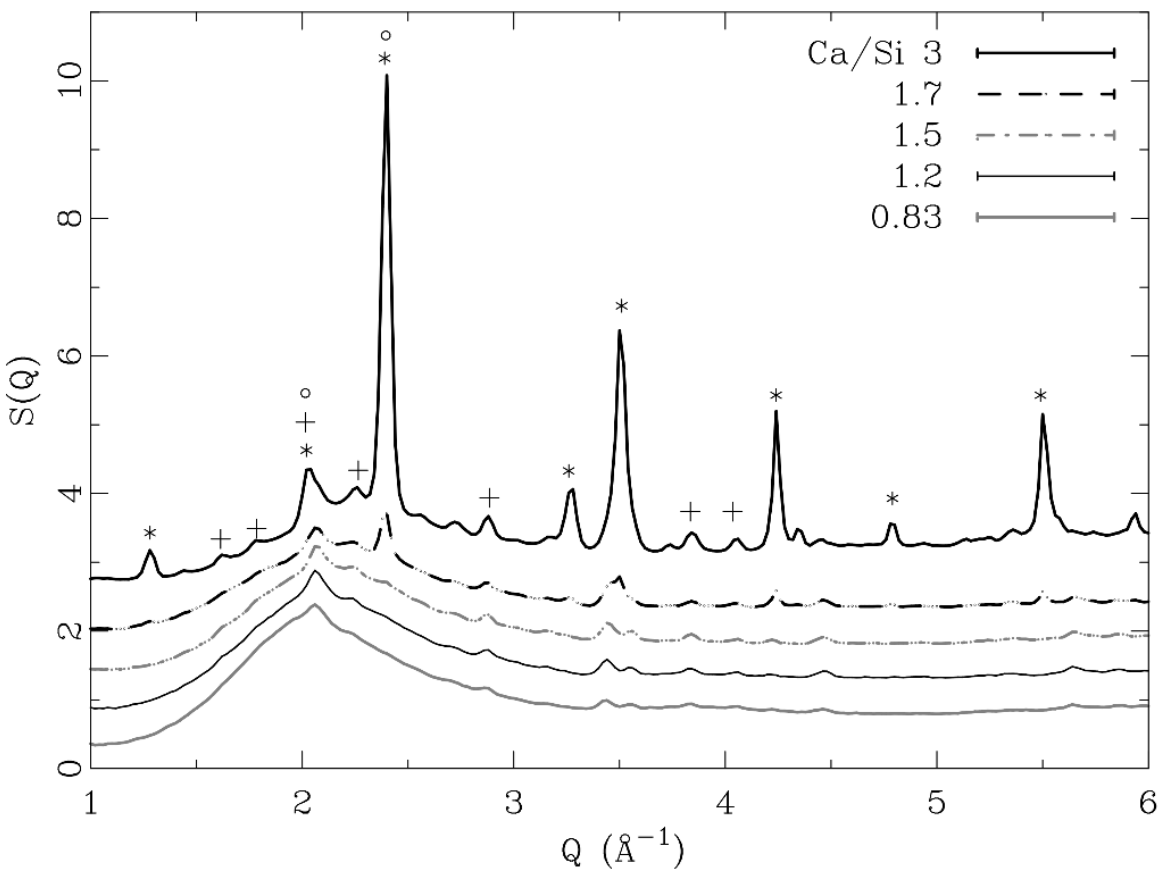




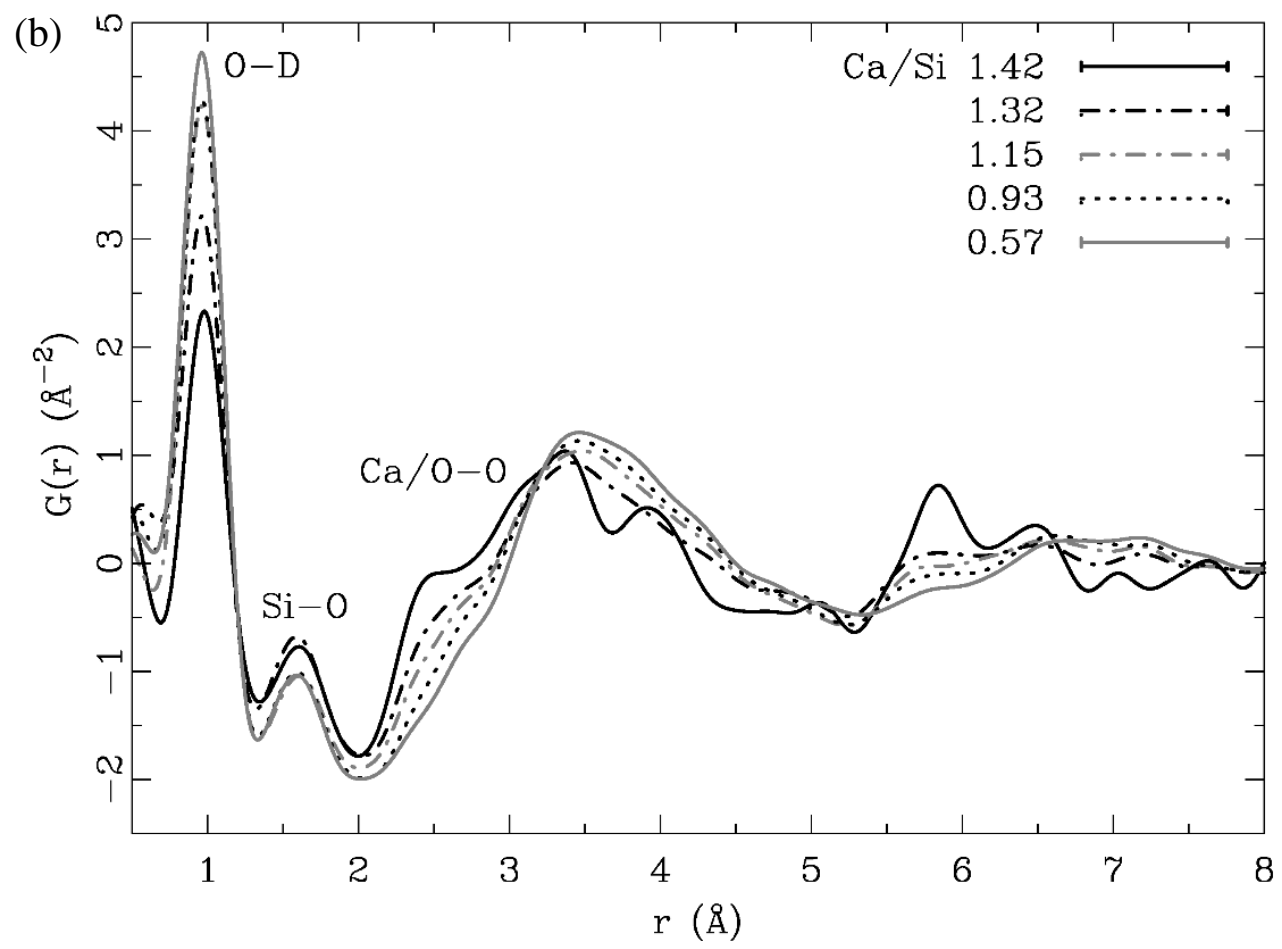

Figure 1. (a) Neutron total scattering functions of C-S-D gels with different $\mathrm{Ca} / \mathrm{Si}$ ratios (the $\mathrm{Ca} / \mathrm{Si}$ ratios are given based on the synthesis stoichiometry, gel $\mathrm{Ca} / \mathrm{Si}$ ratios given in the Table 1). Bragg peaks assignments are as follows: C-S-D $\left(^{\circ}\right), \mathrm{C}_{3} \mathrm{~S}(+)$ and portlandite $(*)$. Offsets have been used to enhance clarity. (b) Pair distribution functions of the C-S-D gels after removal of the crystalline contributions from $\mathrm{C}_{3} \mathrm{~S}$ and portlandite. Nearest-neighbor atom-atom correlations are labelled.

To assess the amount of crystalline $\mathrm{C}_{3} \mathrm{~S}$ and portlandite existing in the C-S-D gel samples, a quantitative analysis of the PDF data using a method to remove the crystalline contributions from $\mathrm{C}_{3} \mathrm{~S}$ and portlandite (if present) has been carried out, revealing the scale factors (and therefore fractional amounts) of these crystalline phases. A detailed description of this method is given in our previous investigation using X-rays [3], with the only difference being that here we carried out 
the refinement on the neutron PDF data. Details on the method are given in the Supplementary Material. The fractional amounts (scale factors) of $\mathrm{C}_{3} \mathrm{~S}$ and portlandite in the C-S-D gel samples are reported in Table 1. Table 1 also reports the fractional amounts obtained using X-ray PDF analysis, obtained in our recent investigation [3], which reveals that neutron PDF analysis is not sensitive to the anhydrous phase (i.e., $\mathrm{C}_{3} \mathrm{~S}$ ). However, for the hydrous phases that contain structural and/or molecular water (OD and $\mathrm{D}_{2} \mathrm{O}$, respectively), such as portlandite, neutron and $\mathrm{X}$-ray PDF analysis report similar phase fractions. 
Table 1. Relative fractional amounts (scale factors) of $\mathrm{C}_{3} \mathrm{~S}$ and portlandite crystalline phases present in samples synthesized using $\mathrm{C}_{3} \mathrm{~S}$ and fumed silica, as determined by refining simulated neutron pair distribution functions to experimental data in the region $40 \leq r \leq 50 \AA$. Agreement with data is given by the $R$-value, as defined in Eq. S.1 (see Supplementary Material for details). The fractional amounts obtained via X-ray pair distribution function analysis [3] are provided in parentheses. Note that the amounts for each sample are relative since the scaling of the neutron pair distribution functions is not absolute due to the hydrogen correction during data reduction.

\begin{tabular}{ccccc}
\hline Sample (Ca/Si ratio) & $\mathrm{C}_{3} \mathrm{~S}^{\mathrm{a}}$ & Portlandite & $\begin{array}{c}\text { Gel Ca/Si } \\
\text { ratio }^{\mathrm{b}}\end{array}$ & R-value $^{\mathrm{c}}$ \\
\hline 0.83 & $0.04(0.39)$ & $0.00(0.00)$ & 0.57 & 0.71 \\
1.2 & $0.07(0.32)$ & $0.00(0.00)$ & 0.93 & 0.72 \\
1.5 & $0.07(0.31)$ & $0.00(0.05)$ & 1.15 & 0.76 \\
1.7 & $0.03(0.25)$ & $0.03(0.09)$ & 1.32 & 0.67 \\
3.0 & $0.15(0.41)$ & $0.34(0.31)$ & 1.42 & 0.28
\end{tabular}

${ }^{\text {a }}$ The low $\mathrm{C}_{3} \mathrm{~S}$ content compared to the values obtained using X-rays is due to the insensitivity of neutron to calcium/silicon in the presence of deuterium. Neutron data refinements performed using the given X-ray fractional amount for $\mathrm{C}_{3} \mathrm{~S}$ (as opposed to those obtained for neutron) results in similar R-values.

${ }^{\mathrm{b}}$ Gel ratios calculated in reference [3].

${ }^{\mathrm{c}}$ The relatively high $\mathrm{R}$-values obtained for low $\mathrm{Ca} / \mathrm{Si}$ ratio samples is due to the lack of distinct atom-atom correlations in the PDF data at high $r$. 
Figure $1 \mathrm{~b}$ contains the neutron PDFs for the C-S-D gels after removal of the crystalline contributions from portlandite and $\mathrm{C}_{3} \mathrm{~S}$, where it is apparent that the low $\mathrm{Ca} / \mathrm{Si}$ ratio samples contain more water via the intensity of the O-D correlation at $0.96 \AA$. Given that these gels were exposed to mild drying conditions prior to measurement (vacuum drying), it is likely that the remaining water in the gels, as seen in Figure $1 \mathrm{~b}$, is situated in the C-S-D gel structure (as deuteroxyls or water in the interlayer spacing) and in gel and small capillary pores. However, it is unlikely that the gels reached equilibrium with respect to water loss, since the thermogravimetry results given in the Supplementary Material reveal that the $\mathrm{D}_{2} \mathrm{O} / \mathrm{Si}$ ratio of the gels is greater than 2, which is the upper limit for interlayer water in the C-S-H layers [21,22]. Hence, longer exposure to the vacuum conditions would have likely resulted in additional changes due to the possible removal of remaining water in the capillary and gel pores. Figure $1 \mathrm{~b}$ shows that the Si-O correlation at $1.60 \AA$ is similar for the different gels in terms of overall intensity (taking into account the differences in the atomic number density, as given by the sloping baseline at low $r$ ). On the other hand, there are significant differences in the $\mathrm{Ca}-\mathrm{O}$ correlation at $\sim 2.44 \AA$ and $\mathrm{O}-\mathrm{O}$ at $\sim 2.7 \AA$ (where a slight inflection point is located in the data). In the X-ray PDFs these correlations were located at $2.40 \AA$ and $\sim 2.7 \AA$, for $\mathrm{Ca}-\mathrm{O}$ and $\mathrm{O}-\mathrm{O}$, respectively [3]. Hence, although the neutron PDF data are most sensitive to the water-containing correlations, there is still information available on the atom-atom correlations containing silicon and calcium.

The C-S-H model proposed by Pellenq et al. [4,5] has been compared to the neutron PDF data for the C-S-D gel with $\mathrm{Ca} / \mathrm{Si}$ ratio of 1.32 using PDFgui [23], revealing that the correlations present between 3 and $4.5 \AA$ are attributed to $\mathrm{Ca}$-Si distances and correlations relating to the water molecules (D-D and O-D), however, assignment of the Ca-Si distances is difficult due to the 
limitations of the C-S-H model, as noted by others [5]. In Figure 1b these correlations are seen to decrease in intensity as the $\mathrm{Ca} / \mathrm{Si}$ ratio increases (apart from $\mathrm{Ca} / \mathrm{Si}$ of 3, which contains residual atom-atom correlations from crystalline portlandite as a result of the subtraction procedure, as was the case for the X-ray data [3] due to the high portlandite content), which implies that the dominant atom-atom distances in this region are from D-D and O-D. On the other hand, the Ca-O/O-O correlations present at $\sim 2.4$ and $2.7 \AA$ are seen to increase in intensity for increasing $\mathrm{Ca} / \mathrm{Si}$ ratio, which is a clear indication of the increasing calcium content in the samples as the $\mathrm{Ca} / \mathrm{Si}$ increases. Lastly, it is important to note that for the correlation present at $1.59 \AA$ assigned to Si-O there will be some contribution from intramolecular D-D distance in $\mathrm{D}_{2} \mathrm{O}$ molecules (1.51 $\mathrm{A}$ ) [24].

\section{Drying-Induced Structural Changes at $110^{\circ} \mathrm{C}(\mathrm{Gel} \mathrm{Ca} / \mathrm{Si}$ of 1.32)}

A previous investigation has been carried out on the structural changes that occur during elevated drying of synthetic C-S-H gels (at temperatures of $\sim 110{ }^{\circ} \mathrm{C}$ ) using reciprocal space analysis (Xray diffraction), which revealed that the $\mathrm{C}-\mathrm{S}-\mathrm{H}$ gel atomic structure tends to undergo a contraction in the $c$ lattice spacing from $\sim 11$ to $9 \AA$, together with an increase in the number of silica $\mathrm{Q}^{2}$ sites (measured by ${ }^{29} \mathrm{Si} \mathrm{NMR}$ ) [14]. Here, complementary structural information has been obtained using neutron PDF analysis, which can probe the evolution of the water-containing correlations. Figure 2 displays the in situ neutron reciprocal space diffraction patterns (Figure 2a) and PDFs (Figure $2 \mathrm{~b})$ for $\mathrm{C}-\mathrm{S}-\mathrm{D}$ gel $(\mathrm{Ca} / \mathrm{Si}$ of 1.32$)$ exposed to $110{ }^{\circ} \mathrm{C}$. The data have been normalized (scaled) to the intensity of the portlandite Bragg peak located at $Q=3.5 \AA^{-1}$ to ensure that the relative changes seen in Figure $2 b$ are a true reflection of local structural changes occurring during heating. This normalization step is necessary since the neutron total scattering data and PDFs were produced without taking into account changes in stoichiometry due to the loss of water. Portlandite 
does not decompose until $\sim 450{ }^{\circ} \mathrm{C}[25]$, which enables this phase to be used as an internal standard at a temperature of $110^{\circ} \mathrm{C}$.

The main change seen in the total scattering patterns (Figure 2a) as C-S-D gel is exposed to 110 ${ }^{\circ} \mathrm{C}$ is the loss in intensity of the broad diffuse peak positioned between $Q$ values of 1 and $3.5 \AA^{-1}$, which is attributed to removal of water from the gel [20]. The neutron PDFs (Figure 2b) directly show this loss of water via the reduction in intensity of the nearest-neighbor correlation (O-D) positioned at $0.95 \AA$. Although this correlation reduces significantly by $5.5 \mathrm{hrs}$, there is still a definite O-D peak present. Hence, further drying at $110{ }^{\circ} \mathrm{C}$ would likely result in additional changes in the local atomic structure, with the rate of decrease in the O-D correlation discussed in the next section. A previous investigation on OPC using nuclear magnetic resonance found that drying at temperatures below $150{ }^{\circ} \mathrm{C}$ results in water still being present in gel pores, although it was unclear if the samples reached constant mass during the drying period or if the drying time was kept constant [26]. Therefore, given that this sample was dried at $110{ }^{\circ} \mathrm{C}$, the changes seen in Figure $2 b$ is due to the removal of water from the pores (capillary and gel pores).

The other major changes in the local structure due to drying at an elevated temperature are the water-containing correlations (O-D and D-D) between 3 and $4.5 \AA$, which are seen to reduce in intensity, and the $\mathrm{Ca}-\mathrm{O}$ and $\mathrm{O}-\mathrm{O}$ correlations between 2 and $3 \AA$, where the overall intensity increases. However, the increase in intensity for the $\mathrm{Ca}-\mathrm{O}$ and $\mathrm{O}-\mathrm{O}$ correlations is attributed to a reduction in the atomic number density $\left(\rho_{o}\right)$ due to the removal of water from the material combined with the loss of $\mathrm{O}-\mathrm{O}$ correlations associated with the hydrogen bonding of water molecules, which account for the emergence of a pronounced peak at $\sim 2.5 \AA$. Since the $\mathrm{Ca}-\mathrm{O}$ 
correlation in C-S-D occurs at $2.40 \AA$ (and $~ 2.35 \AA$ in portlandite) [27], and the O-O correlation is positioned at $\sim 2.7 \AA$, this local atomic ordering at $2.5 \AA$ in Figure $2 b$ is due the presence of both the $\mathrm{Ca}-\mathrm{O}$ and $\mathrm{O}-\mathrm{O}$ correlations. Although it cannot be ruled out that part of the changes seen in the $\mathrm{Ca}-\mathrm{O} / \mathrm{O}-\mathrm{O}$ correlations may be due to changes in the local bonding environment of the calcium ions, analysis of the higher $r$ correlations (see Supplementary Material for details) reveals no change in the long-range ordering due to drying. Furthermore, to assess which atom-atom correlations are lost during the in situ drying measurement, a difference curve analysis of the neutron PDF data has been performed, with the results showing that the difference curves are very similar to bulk $\mathrm{D}_{2} \mathrm{O}$ PDF data available in the literature [28] (see Supplementary Material for further details) which implies that the only changes occurring in the sample are due to the removal of water. Hence, drying at $110{ }^{\circ} \mathrm{C}$ does not significantly alter the calcium silicate layered structure for the gel studied here. 
(a)
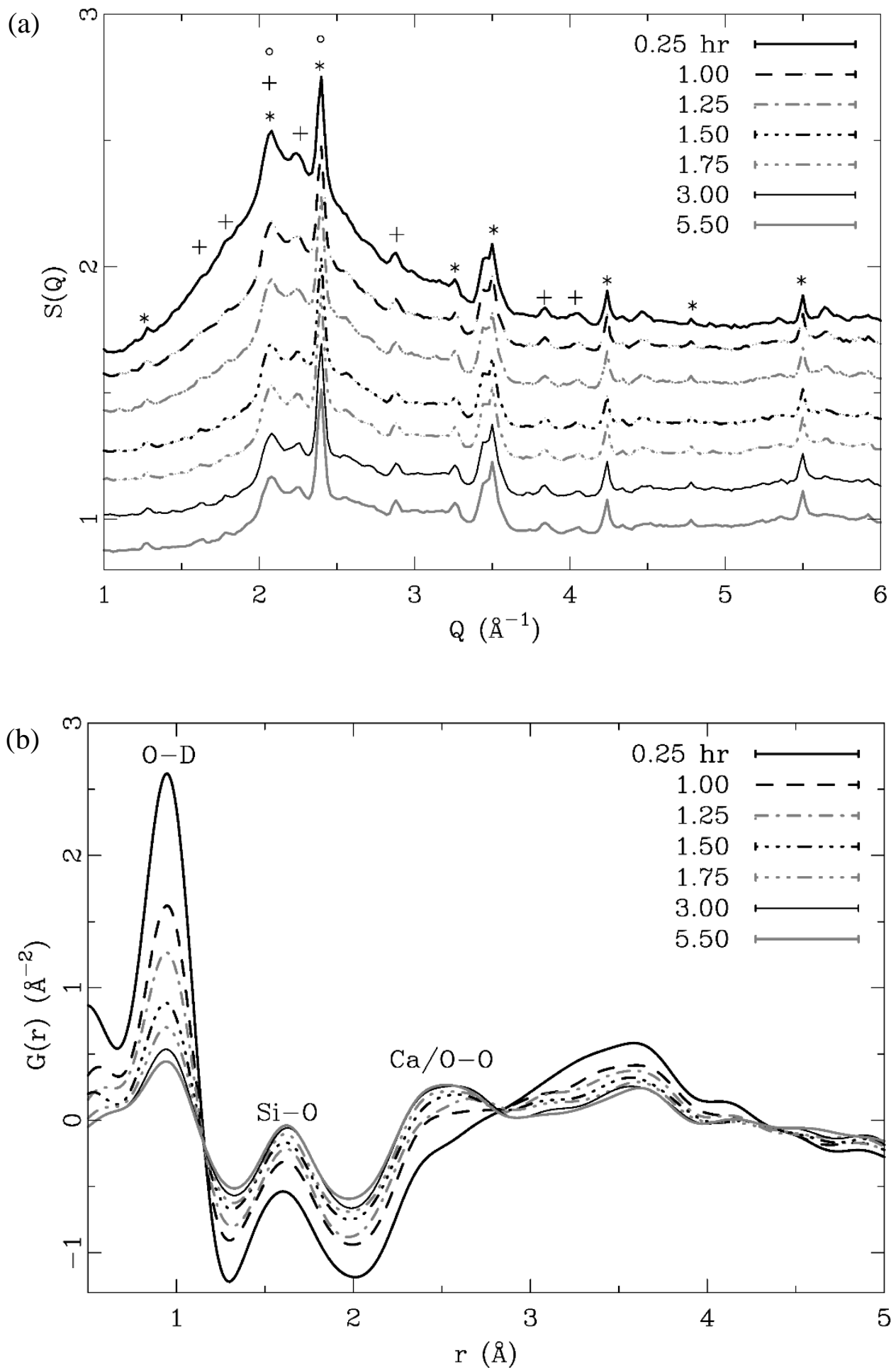

Figure 2. (a) Neutron total scattering functions of C-S-D gel with a $\mathrm{Ca} / \mathrm{Si}$ ratio of 1.32 (ratio of 1.7 in sample) exposed to drying conditions at $110^{\circ} \mathrm{C}$. Bragg peaks assignments are as follows: C-S-D $\left({ }^{\circ}\right), \mathrm{C}_{3} \mathrm{~S}(+)$ and portlandite $(*)$. Offsets have been used to enhance clarity, and the 
denoted times correspond to the exposure duration. (b) Pair distribution functions of the C-S-D gel. Nearest-neighbor atom-atom correlations are labelled.

\section{Kinetics of Dehydration at $110^{\circ} \mathrm{C}(\mathrm{Gel}$ with $\mathrm{Ca} / \mathrm{Si}$ of 1.32)}

The rate of water loss from C-S-D gel when exposed to $110^{\circ} \mathrm{C}$ can be determined via the change in intensity of the O-D correlation seen in Figure 2b. The O-D correlation maximum intensity is plotted as a function of time in Figure 3, where it is apparent that the rate of water loss from the sample decreases after $\sim 2 \mathrm{hrs}$ of drying at $110{ }^{\circ} \mathrm{C}$. Furthermore, the rate of water loss can be accurately described using two linear regions, as opposed to a single rate expression $\left(1^{\text {st }}\right.$ or $2^{\text {nd }}$ order), and therefore the removal of water molecules from the sample consists of two processes described by $0^{\text {th }}$-order rate expressions (constant rate periods). Cong and Kirkpatrick reported a change in the $c$ axis lattice spacing associated with the $\mathrm{C}-\mathrm{S}-\mathrm{H}$ gel when heated at $110{ }^{\circ} \mathrm{C}$ in a vacuum oven [14]; however, analysis of the neutron PDF data over an $r$ range of 10 to $30 \AA$ reveals that the atomic ordering of the gel remains unchanged as water is removed from the gel pores (i.e., no contraction of the $c$ axis is visible, see Supplementary Material for details). 


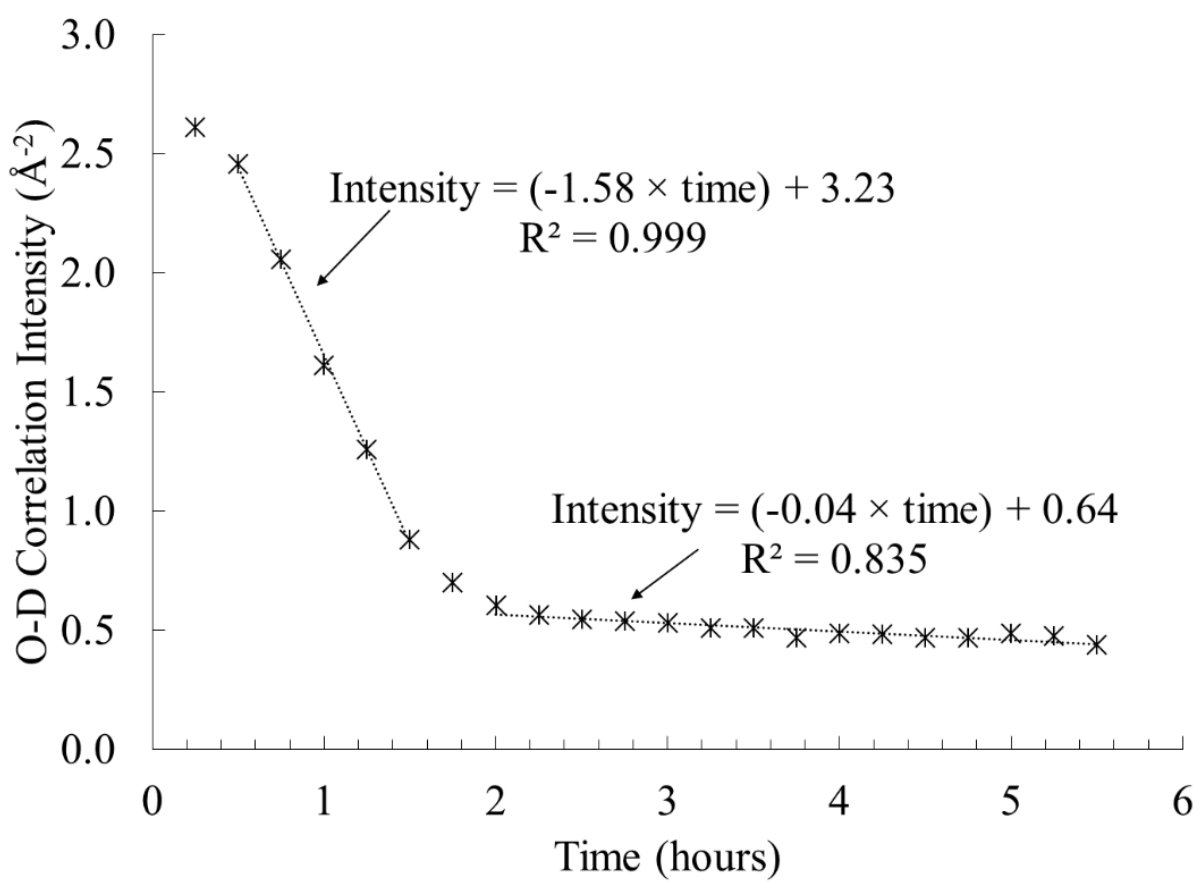

Figure 3. Intensity of the O-D correlation during elevated drying $\left(110^{\circ} \mathrm{C}\right)$ for C-S-D gel with $\mathrm{Ca} / \mathrm{Si}$ of 1.32 , determined from neutron pair distribution function data.

\section{High Temperature Structural Behavior (Gel Ca/Si of 0.57)}

The local structural changes of C-S-D gel in response to exposure to high temperatures $\left(>200{ }^{\circ} \mathrm{C}\right.$ ) are important from a macroscopic structural integrity viewpoint, and therefore it is important to have a detailed understanding of the atomic structure of C-S-D gel and changes that occur in response to heating. An investigation on the structural changes (crystalline phases) using neutron diffraction revealed that the $\mathrm{C}-\mathrm{S}-\mathrm{H}$ gel is altered in response to the elevated temperatures via formation of larnite (monoclinic $\mathrm{Ca}_{2} \mathrm{SiO}_{4}$ ) [17]. ${ }^{29} \mathrm{Si} \mathrm{NMR}$ experiments have reported conflicting results regarding the changes in $\mathrm{Q}^{1} / \mathrm{Q}^{2}$ silicate sites in $\mathrm{C}-\mathrm{S}-\mathrm{H}$ gel at moderate temperatures (110 and $200^{\circ} \mathrm{C}$ ) with one investigation reporting an increase in $\mathrm{Q}^{2}$ silicate sites with temperature [14], whilst another stating that these sites decrease [11]. However, these gels were made via different 
synthesis methods (synthetic C-S-H gel versus C-S-H gel in hydrated OPC) and have different $\mathrm{Ca} / \mathrm{Si}$ ratios, which may explain the conflicting results. Nevertheless, additional information on the local structural changes occurring in the C-S-H gel is warranted to assess how this gel responds to elevated temperatures.

Figure 4 contains the neutron diffraction data for a C-S-D gel with $\mathrm{Ca} / \mathrm{Si}$ ratio of 0.57 exposed to elevated temperatures (up to $650^{\circ} \mathrm{C}$ ), with Figure 4 a containing the total scattering data (reciprocal space) and Figures $4 \mathrm{~b}$ and $4 \mathrm{c}$ the real-space neutron PDF data, scaled to account for water loss. Due to the absence of portlandite in this sample, which, even if present would decompose at 450 ${ }^{\circ} \mathrm{C}, \mathrm{C}_{3} \mathrm{~S}$ was used as an internal standard for normalization, as it is stable up to a temperature of $685{ }^{\circ} \mathrm{C}$ [29]. A C-S-D sample without the presence of portlandite was analyzed to ensure that the changes measured using neutron PDF analysis were due to changes in the C-S-D gel rather than an interaction between C-S-D gel and other phases in the sample. Figure $4 \mathrm{a}$ reveals that a significant amount of water is removed from the sample after $3 \mathrm{hrs}$ at $110^{\circ} \mathrm{C}$, which is seen via the reduced intensity of the diffuse scattering attributed to the water correlations (between 1 and $\left.3.5 \AA^{-1}[20]\right)$. An additional reduction in the diffuse scattering is visible between 110 and $250{ }^{\circ} \mathrm{C}$, with higher temperatures (up to $650^{\circ} \mathrm{C}$ ) revealing little change in the measured scattering patterns. Apart from the significant reduction in diffuse scattering during the in situ temperature measurement due to the removal of water from the sample, there are additional changes visible in Figure 4a, specifically the emergence of weak diffuse scattering located at $Q$ values of 1.2 and $3.15 \AA^{-1}$. Phase identification analysis of the weak diffuse scattering and the Bragg peaks visible in the patterns revealed that the scattering can be attributed to either a dicalcium silicate phase 
(similar to larnite, $\mathrm{C}_{2} \mathrm{~S}$ ) or $9 \AA$ tobermorite; however, gamma- $\mathrm{C}_{2} \mathrm{~S}$, calcite, lime, wollastonite, and larger spacing tobermorite ( 11 and $14 \AA$ ) are not present in the sample.

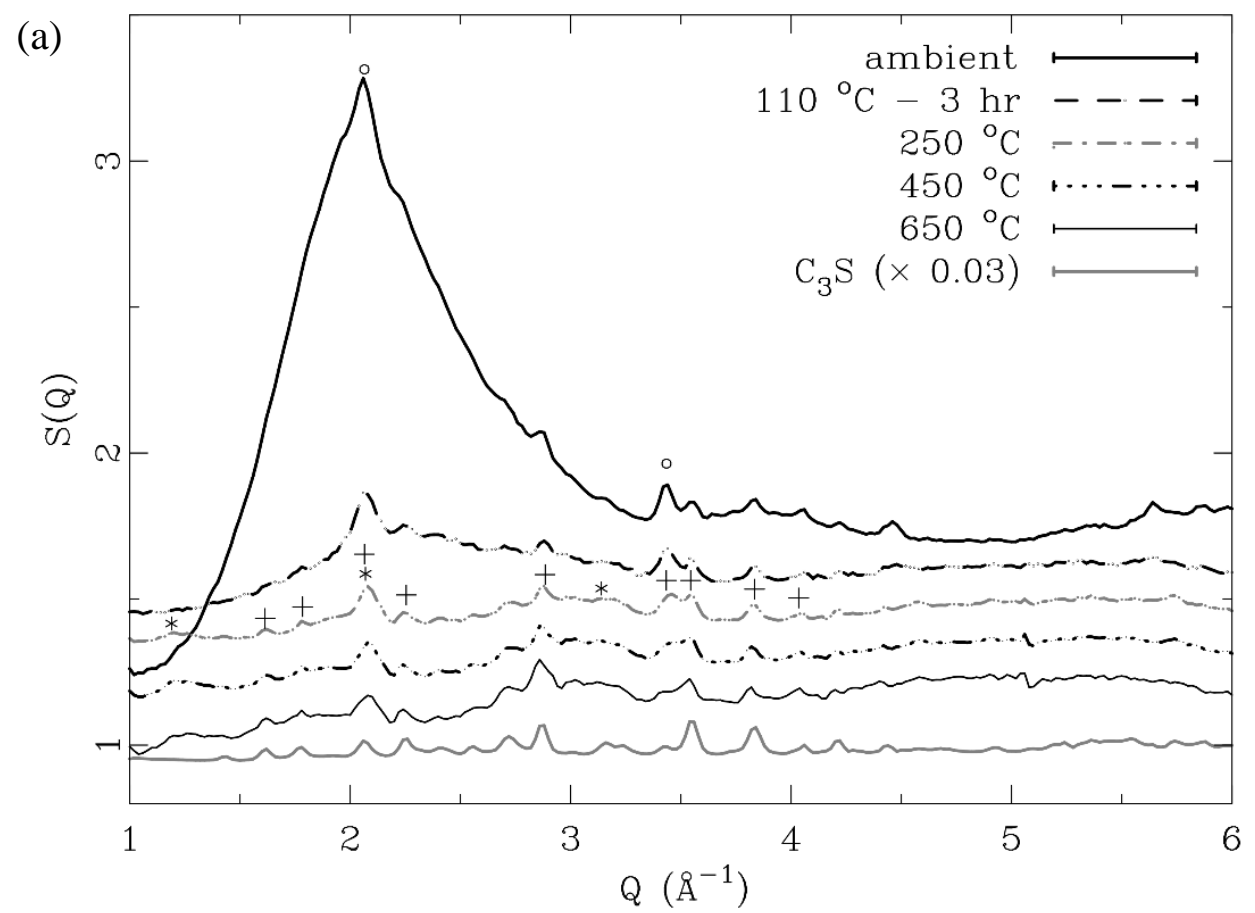

(b)

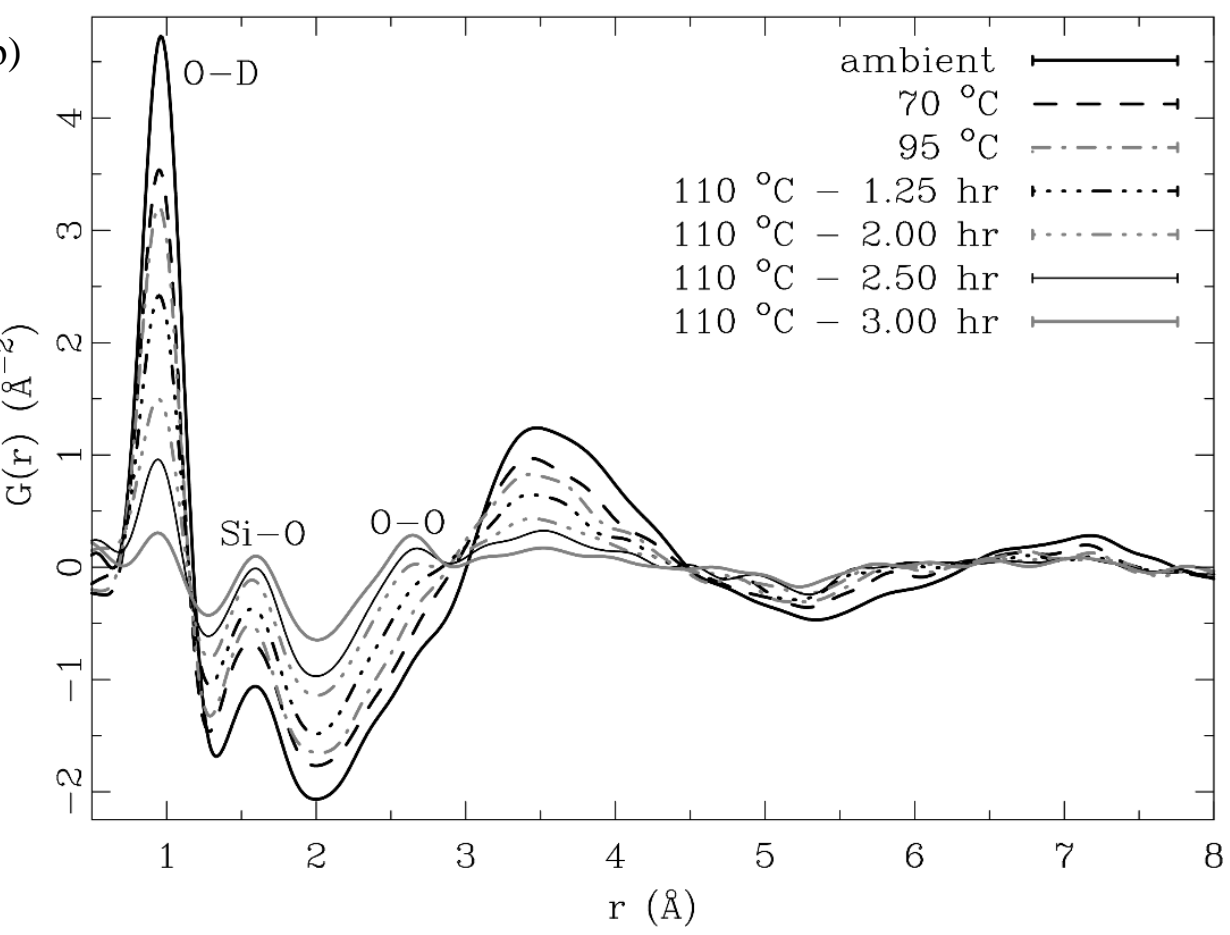


(c)

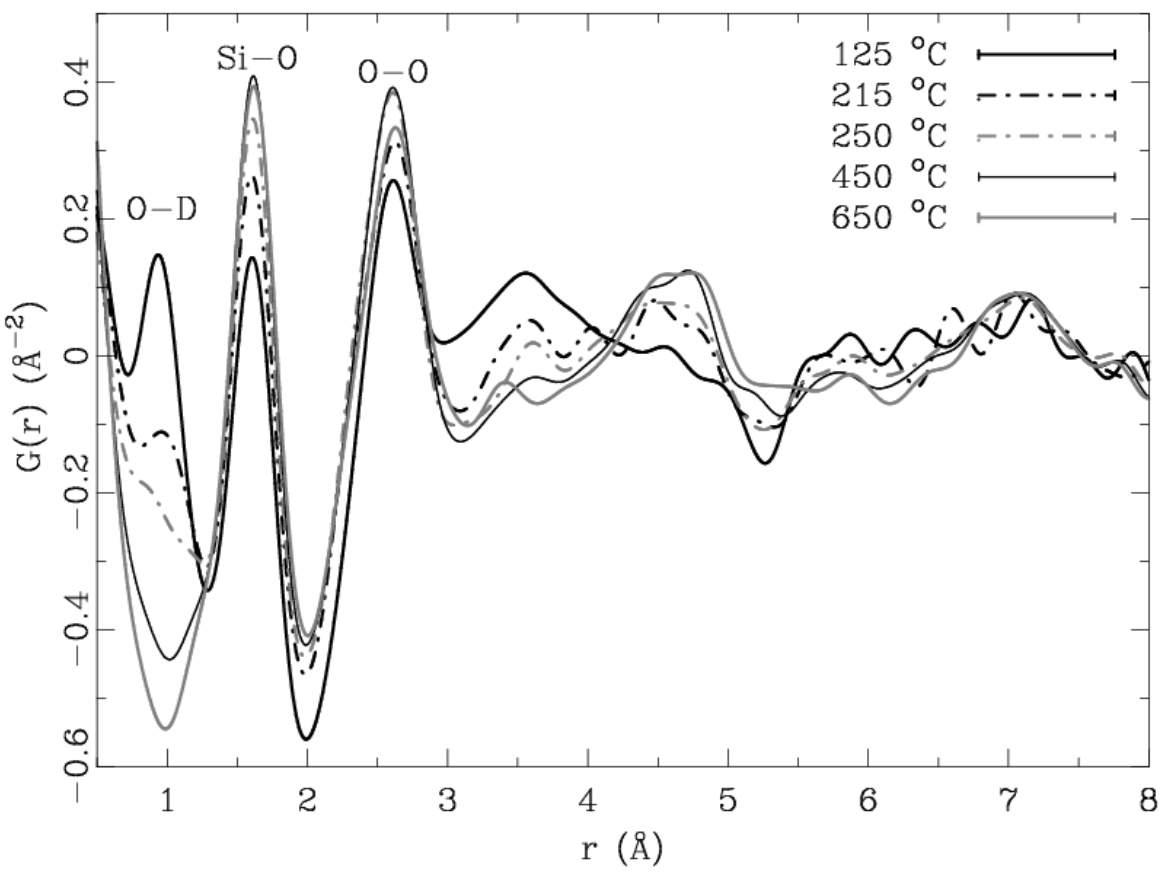

Figure 4. (a) Neutron total scattering functions of C-S-D gel with a Ca/Si ratio of 0.57 (ratio of 0.83 for the sample) exposed to temperatures up to $650{ }^{\circ} \mathrm{C}$. Bragg peaks assignments are as follows: C-S-D $\left(^{\circ}\right), \mathrm{C}_{3} \mathrm{~S}(+)$ and $9 \AA$ A tobermorite/ $\mathrm{C}_{2} \mathrm{~S}(*)$. Offsets have been used to enhance clarity, and the denoted times correspond to the exposure duration at $110{ }^{\circ} \mathrm{C}$. (b) Pair distribution functions of the C-S-D gel ranging in temperatures up to $110^{\circ} \mathrm{C}$. Nearest-neighbor atom-atom correlations are labelled. (c) Pair distribution functions above $110^{\circ} \mathrm{C}$.

As seen in Figure $4 b$, at a temperature of $110{ }^{\circ} \mathrm{C}$ the atomic structure of C-S-D gel with a Ca/Si ratio of 0.57 is seen to go through similar structural transitions to the gel with $\mathrm{Ca} / \mathrm{Si}$ of 1.32 , where the atomic number density is seen to decrease as water is removed from the gel, and there are significant reductions in intensity associated with the water-containing correlations (O-D at 0.96 $\AA$, and O-D and D-D between 3 and $4.5 \AA$ ). There is a slight shift in the nearest-neighbor O-D correlation from $0.96 \AA$ at ambient temperature to $0.94 \AA$ after $3 \mathrm{hrs}$ at $110{ }^{\circ} \mathrm{C}$. Figure $4 \mathrm{c}$ shows 
that all the water molecules and/or deuteroxyl units have been removed from the structure by 250 ${ }^{\circ} \mathrm{C}$ as there is no discernible O-D correlation at $\sim 0.94 \AA$ in the neutron PDF. Also apparent in Figure $4 \mathrm{~b}$ is the emergence of the $\mathrm{O}-\mathrm{O}$ correlation at $2.65 \AA$; however, the positioning of this peak implies that there is reduced contribution from a Ca-O correlation at $\sim 2.4 \AA$ compared to the C-SD gel with $\mathrm{Ca} / \mathrm{Si}$ ratio of 1.32 , which is attributed to the lower calcium content of this C-S-D gel.

Figure $4 c$ contains the neutron PDFs for the C-S-D gel (Ca/Si of 0.57$)$ exposed to higher temperatures $\left(125\right.$ to $6500^{\circ} \mathrm{C}$ ). The $650^{\circ} \mathrm{C}$ PDF data set has been scaled using the same scaling factor as that of $450^{\circ} \mathrm{C}$ since $\mathrm{C}_{3} \mathrm{~S}$ exhibits a phase transformation at $\sim 685^{\circ} \mathrm{C}$ (triclinic to triclinic) [29]. Scaling of the $650{ }^{\circ} \mathrm{C}$ PDF data set using the $\mathrm{C}_{3} \mathrm{~S}$ content resulted in Si-O and O-O correlations that were significantly more intense than the other PDF data sets. Hence, even at 650 ${ }^{\circ} \mathrm{C}$ the crystal structure of $\mathrm{C}_{3} \mathrm{~S}$ has undergone some degree of reorganization when placed at these conditions for an extended period of time ( $3 \mathrm{hrs})$. Figure $4 \mathrm{c}$ displays an increase in the Si-O and O-O correlations with increasing temperature together with decreases in the nearest-neighbor OD correlation and the water-containing correlations between 3 and $4.5 \AA$. By $215{ }^{\circ} \mathrm{C}$ the atomic number density has reached a steady-state, and therefore further increase in correlations past this temperature can be attributed to changes in the local atomic ordering of the calcium silicate layers, as opposed to a change in the density of the material. The emergence of new correlations between $\sim 4$ and $5 \AA$ is due to increased ordering in the second nearest-neighbor $\mathrm{Ca}-\mathrm{O}$ correlations as determined using the structure models fitted to the 250 and $650{ }^{\circ} \mathrm{C}$ PDFs as described below.

Comparison of the 250 and $650{ }^{\circ} \mathrm{C}$ neutron PDF data sets with the atomic structures of larnite and $9 \AA$ Å tobermorite using PDFgui [23] reveals that the local atomic structure of this heated C-S-D gel 
is best fit using a multiphase structural model consisting of both crystalline larnite and nanocrystalline $9 \AA$ A tobermorite (see Figure 5 and Table 2 for results), as opposed to either phase individually. It should be mentioned that the formation of larnite (beta- $\mathrm{C}_{2} \mathrm{~S}$ ) in systems without additives (such as sodium and chromium) is only seen to occur during cooling (after heating to $1400{ }^{\circ} \mathrm{C}$ ) [30], and since these temperatures are not reached during the in situ neutron PDF experiment, the formation of larnite is extremely unlikely. However, the local bonding in larnite (calcium nesosilicate) provides the best fit to the neutron PDF data (compared to the gamma- $\mathrm{C}_{2} \mathrm{~S}$, the stable $\mathrm{C}_{2} \mathrm{~S}$ phase below $\sim 740{ }^{\circ} \mathrm{C}$ during heating), indicating that this bonding arrangement is likely present in the heated C-S-D gel, albeit in relatively low amounts (as depicted in Table 2).

As the temperature increases from 250 to $650{ }^{\circ} \mathrm{C}$ the amount of $\mathrm{C}_{2} \mathrm{~S}$ remains relatively unchanged, while an increase in the $9 \AA$ tobermorite occurs (Table 2). Furthermore, the long range ordering decreases with increasing temperature, as determined via a reduction in the nanocrystallite size used for modeling $9 \AA$ tobermorite (from approximately 17 to $13 \AA$ ). Hence, the $9 \AA$ tobermorite phase is becoming increasingly disordered as heating progresses. Given that the silicate speciation of $9 \AA$ tobermorite is $\mathrm{Q}^{2}$ and $\mathrm{Q}^{0}$ for larnite, these results suggest that as the temperature increases past $250{ }^{\circ} \mathrm{C}$, the silica is becoming more polymerized (higher $\mathrm{Q}^{\mathrm{n}}$ speciation due to an increase in the amount of $9 \AA$ tobermorite). 


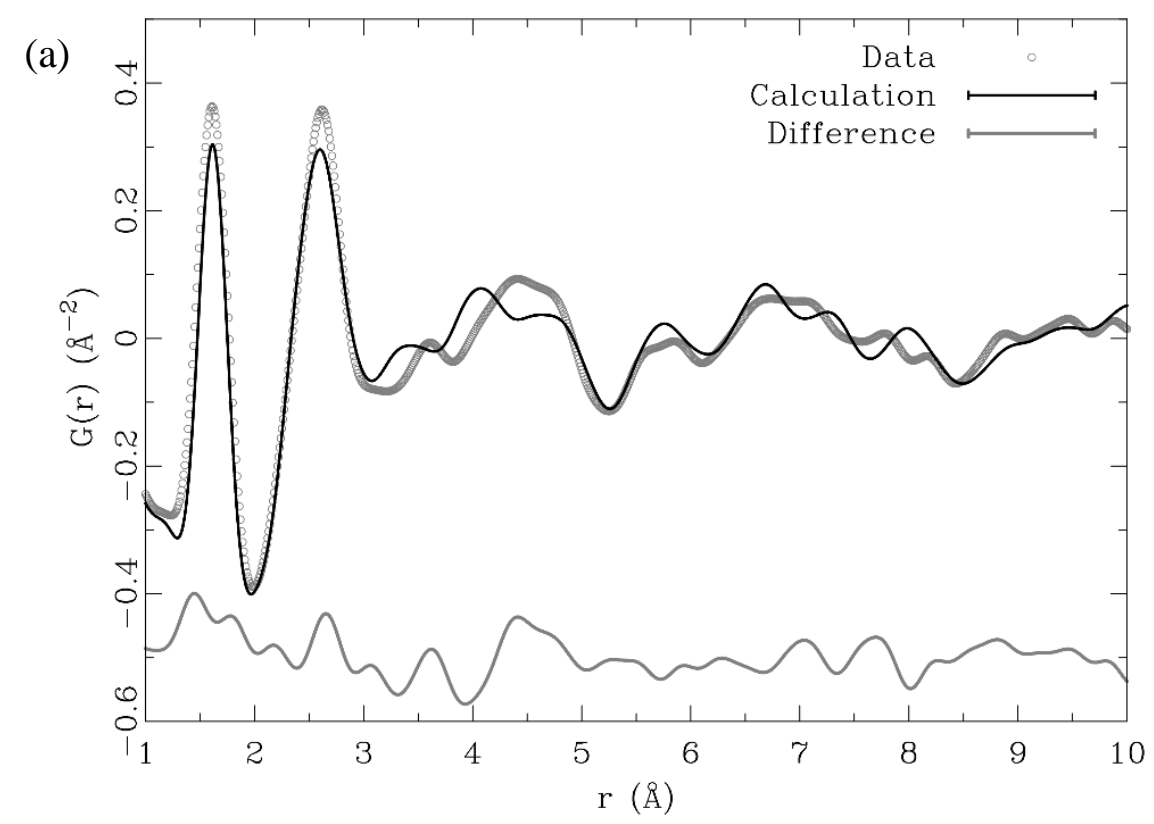

(b)

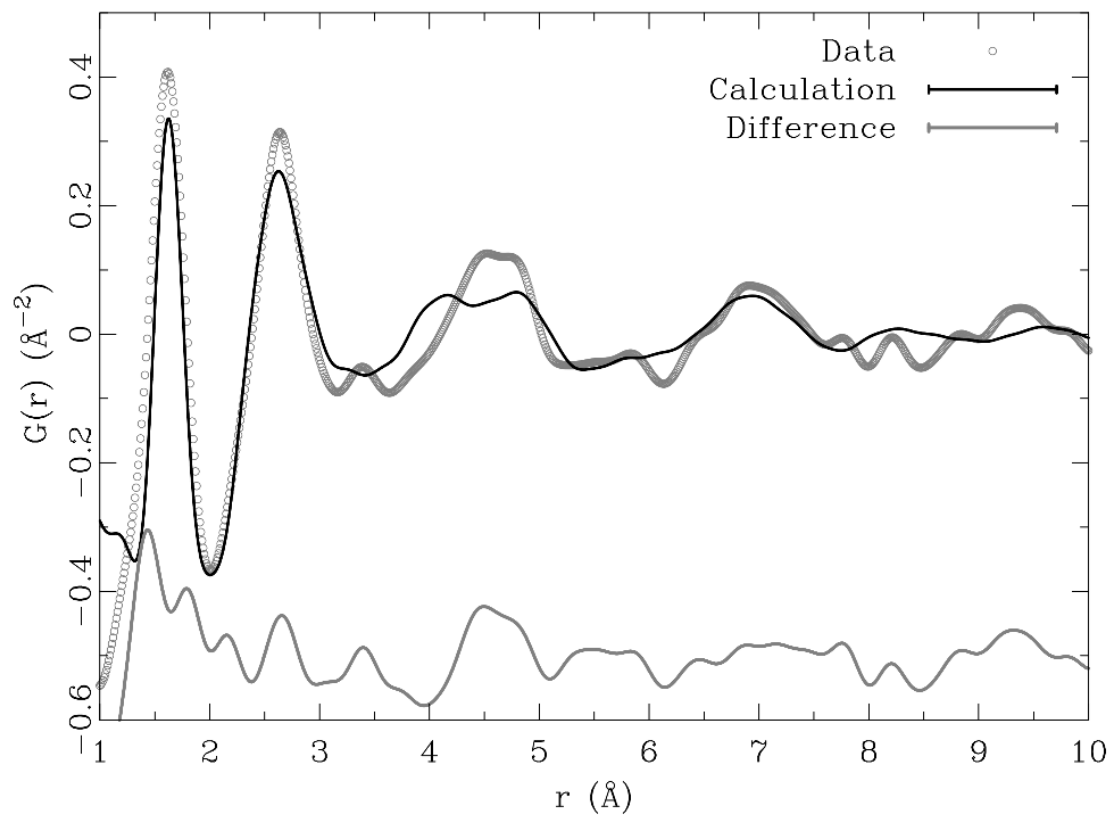

Figure 5. Neutron pair distribution functions of a C-S-D gel with $\mathrm{Ca} / \mathrm{Si}$ of 0.57 heated to (a) 250 and (b) $650{ }^{\circ} \mathrm{C}$. The experimental pair distribution functions have been fitted using PDFgui and a two phase model of $9 \AA$ tobermorite and larnite. Correlations relating to $\mathrm{C}_{3} \mathrm{~S}$ have been removed from the experimental data prior to the fitting procedure (via matching the experimental data for 
the heated gel with the experimental data set of $\mathrm{C}_{3} \mathrm{~S}$ between 35 and $50 \AA$, and then performing the subtraction).

Table 2. Relative fractional amounts (scale factors) of $9 \AA$ tobermorite, larnite and $\mathrm{C}_{3} \mathrm{~S}$ present in the heated C-S-D sample with $\mathrm{Ca} / \mathrm{Si}$ of 0.83 (gel ratio of 0.57 ). Agreement with data for the tobermorite/larnite fits is given by the $R_{w}$-value, as defined in PDFgui [23], for a fitting range of 1.3 to $30.0 \AA$.

\begin{tabular}{|c|c|c|c|c|c|c|}
\hline \multirow{2}{*}{$\begin{array}{c}\text { Sample } \\
\left({ }^{\circ} \mathrm{C}\right)\end{array}$} & \multirow{2}{*}{$\begin{array}{c}9 \AA \\
\text { tobermorite }\end{array}$} & \multirow[t]{2}{*}{ Larnite } & \multirow[t]{2}{*}{$\mathrm{C}_{3} \mathrm{~S}$} & \multirow[t]{3}{*}{$\mathrm{R}_{\mathrm{w}}$-value } & \multicolumn{2}{|c|}{$9 \AA$ tobermorite } \\
\hline & & & & & $c$ lattice & Crystallite \\
\hline & & & & & parameter $(\AA)$ & $\operatorname{size}(\AA)$ \\
\hline 250 & 0.28 & 0.03 & 0.03 & 0.37 & 9.6 & 17 \\
\hline 650 & 0.31 & 0.03 & 0.03 & 0.45 & 9.5 & 13 \\
\hline
\end{tabular}

Kinetics of Dehydration at and Above $110^{\circ} \mathrm{C}(\mathrm{Gel} \mathrm{Ca/Si}$ of 0.57)

The evolution of the nearest-neighbor O-D correlation for the heated C-S-D gel $(\mathrm{Ca} / \mathrm{Si}$ ratio of 0.57) is given in Figure 6, where Figure 6 reports the O-D correlation along with the temperature profile as a function of time. As was the case for the C-S-D gel (Ca/Si ratio of 1.32) heated at 110 ${ }^{\circ} \mathrm{C}$, where two constant rate periods were associated with the removal of water from the sample, these data (Figure 6) also reveal the existence of two $0^{\text {th }}$-order rate periods, albeit the data are relatively noisy at lower temperatures $\left(<110^{\circ} \mathrm{C}\right)$. 
By $250{ }^{\circ} \mathrm{C}$ all the water has been removed from the sample, as no discernible O-D correlation is present in the neutron PDF data at this temperature (Figure 4c). This coincides with the emergence of the broad diffuse peak in the total scattering patterns in Figure $4 \mathrm{a}$, attributed to $9 \AA$ tobermorite $/ \mathrm{C}_{2} \mathrm{~S}$, and the increase in ordering in the $\mathrm{Ca}-\mathrm{O}$ correlation positioned at $\sim 4.7 \AA$ in the neutron PDF data (Figure 4c). Hence, this data supports the findings of previous investigations on C-S-H gel [14] and tobermorite $[15,16]$, where the removal of interlayer water from these materials due to heating can lead to a collapse of the c-axis from 11 to $9 \AA$. Associated with this collapse is a change in the nearest-neighbor bonding environment of the calcium ions in the interlayer spacing. Initially, these ions are partially solvated by water molecules, and therefore, although the nearest-neighbor $\mathrm{Ca}-\mathrm{O}$ correlation is well-defined at $\sim 2.4 \AA$, the longer distances between the calcium ions and the oxygens associated with the silicate layers (Ca-O at $\sim 4.7 \AA$ ) may not give rise to distinct atom-atom correlations in the neutron PDF data due to local disorder in the structure. However, once the interlayer water molecules are removed, and the nearest-neighbor $\mathrm{Ca}-\mathrm{O}$ distance is dominated by interactions between calcium ions and the oxygens associated with the silicate layers, additional Ca-O correlations might appear at higher $r$ spacing (at $\sim 4.7 \AA$ ) due ordering with the other oxygen atoms existing in the silica polyhedra (e.g., second and third nearest-neighbors). Furthermore, similar $\mathrm{Ca}-\mathrm{O}$ distances are present in the crystal structure of larnite, which will also contribute to these correlations present in the neutron PDF data at $\sim 250$ ${ }^{\circ} \mathrm{C}$ and above. 


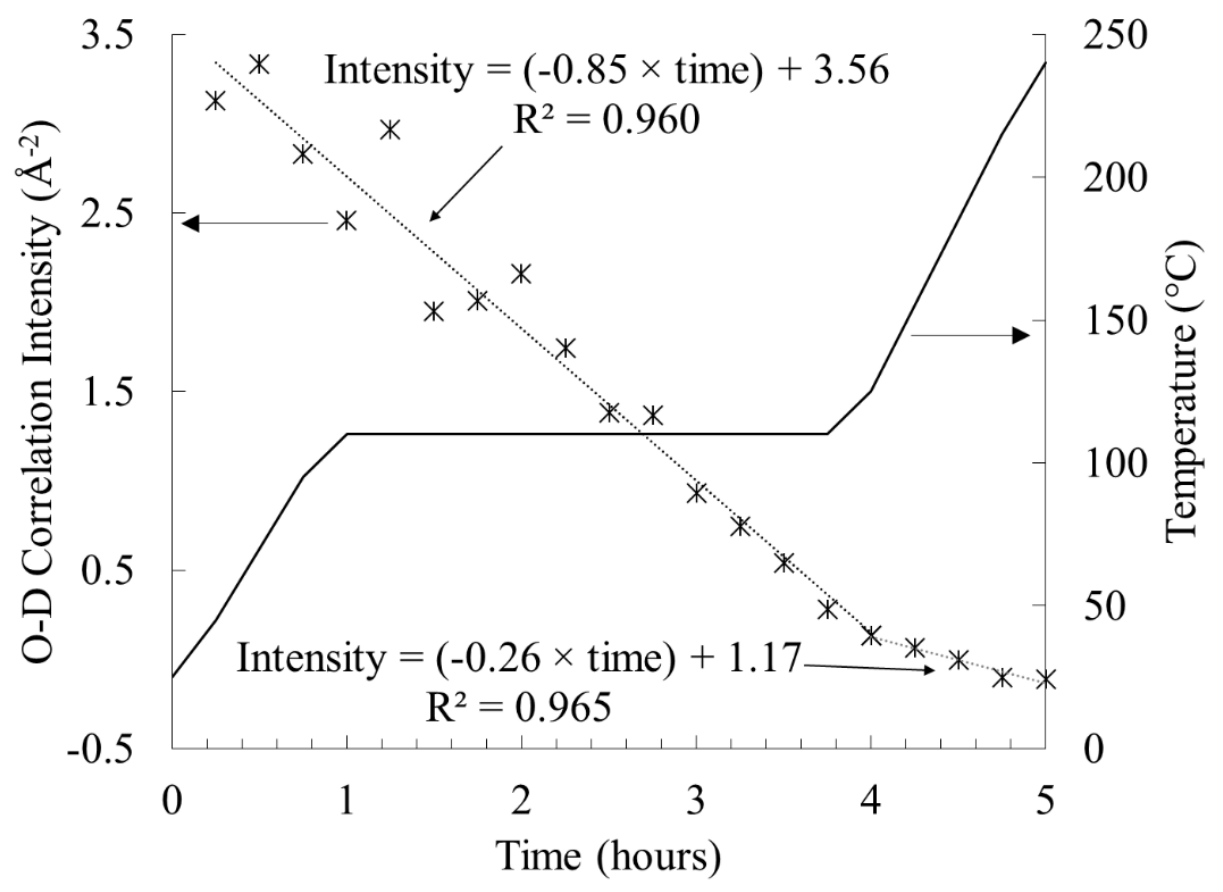

Figure 6. Intensity of the O-D correlation during elevated drying $\left(110^{\circ} \mathrm{C}\right.$ and above) for C-S-D gel with $\mathrm{Ca} / \mathrm{Si}$ of 0.57 , determined from neutron pair distribution function data.

The thermal decomposition of C-S-D gel resulting in the formation of nanosized $9 \AA$ tobermorite and a $\mathrm{C}_{2} \mathrm{~S}$ phase (similar bonding environment to larnite) has not been reported extensively in the literature for OPC pastes and model crystalline phases (11 and $14 \AA$ tobermorite), potentially due to the similarities in Bragg scattering attributed to these phases. However, ${ }^{29} \mathrm{Si}$ NMR experiments on ex situ heated OPC pastes by Alonso and Fernandez revealed the formation of a nesosilicate (i.e., $\mathrm{Q}^{0}$ speciation) described as disordered larnite at temperature of $200^{\circ} \mathrm{C}$ and above [11]. Hence, this investigation corroborates the findings of Alonso and Fernandez [11], and highlights the advantage of using PDF analysis in addition to conventional diffraction studies to obtain a better understanding of the structural transitions that occur during complex reactions such as C-S-D gel 
decomposition. Additional characterization using complementary spectroscopic techniques such as infrared and Raman spectroscopy and nuclear magnetic resonance at elevated temperatures would enable additional information on the local bonding environments to be obtained, and therefore provide independent evidence on the structural transitions that occur upon heating.

\section{Conclusions}

Neutron PDF analysis has been utilized to investigate the local atomic bonding existing in synthetic C-S-D gels with different $\mathrm{Ca} / \mathrm{Si}$ ratios, together with the changes in local structure of CS-D gel that occur during (i) drying at $110{ }^{\circ} \mathrm{C}$, and (ii) exposure up to a temperature of $650{ }^{\circ} \mathrm{C}$. The results show that neutron PDF analysis is extremely sensitive to the water-containing correlations in C-S-D gels, specifically the nearest-neighbor O-D correlation at $\sim 0.96 \AA$, and the O-D and D-D correlations between 3 and $4.5 \AA$. As the calcium content increases in the C-S-D gels the overall water content is seen to decrease, in agreement with the additional water used during synthesis for the low $\mathrm{Ca} / \mathrm{Si}$ gels.

Exposure to elevated drying conditions $\left(110^{\circ} \mathrm{C}\right)$ causes a significant loss of water from C-S-D gel, which has been quantified via the reduction in intensity of the O-D correlation. Analysis of the kinetics of dehydration at $110^{\circ} \mathrm{C}$ reveals the existence of two constant rate periods, with later times corresponding to a lower rate of dehydration. Higher temperatures $\left(>110^{\circ} \mathrm{C}\right)$ result in the removal of additional water, which is accompanied by a collapse of the interlayer spacing to $9.6 \AA$ and emergence of a secondary dicalcium silicate phase. In contrast to reciprocal space analysis, where the diffraction peaks associated with these two crystalline phases regularly coincide, the local structural information in real space is able to better distinguish between these two phases $(9.6 \AA$ 
tobermorite and dicalcium silicate with local structure similar to larnite), enabling the relative phase fractions to be established.

\section{Acknowledgement}

This work was financially supported by the Princeton E-ffiliates Partnership award, Andlinger Center for Energy and the Environment (Princeton University) and the National Science

Foundation (NSF) Materials Research Science and Engineering Center program through the Princeton Center for Complex Materials (DMR-1420541). The author would like to acknowledge Dr. Monika Hartl and Dr. Luke Daemen with advice and assistance during sample synthesis, Dr. Jörg Neuefeind, Dr. Mikhail Feygenson and Mr. John Carruth for support and assistance on the NOMAD instrument at the Spallation Neutron Source, ORNL, and Mr. Michael Brusoski, Mr. Xie Xie and Prof. John Provis for assistance during the neutron experiments. This research at ORNL's Spallation Neutron Source was sponsored by the Scientific User Facilities Division, Office of Basic Energy Sciences, U.S. Department of Energy.

\section{References}

[1] I.G. Richardson, J. Skibsted, L. Black, R.J. Kirkpatrick, Characterisation of cement hydrate phases by TEM, NMR and Raman spectroscopy, Adv. Cem. Res., 22 (2010) 233-248.

[2] L.B. Skinner, S.R. Chae, C.J. Benmore, H.R. Wenk, P.J.M. Monteiro, Nanostructure of calcium silicate hydrates in cements, Phys. Rev. Lett., 104 (2010) 195502.

[3] C.E. White, L.L. Daemen, M. Hartl, K. Page, Intrinsic differences in atomic ordering of calcium (alumino)silicate hydrates in conventional and alkali-activated cements, Cem. Concr. Res., 67 (2015) 66-73. 
[4] R.J.M. Pellenq, A. Kushima, R. Shahsavari, K.J. Van Vliet, M.J. Buehler, S. Yip, F.J. Ulm, A realistic molecular model of cement hydrates, Proc. Natl. Acad. Sci. U.S.A., 106 (2009) 1610216107.

[5] I.G. Richardson, The importance of proper crystal-chemical and geometrical reasoning demonstrated using layered single and double hydroxides, Acta Crystallogr. Sect. B, 69 (2013) $150-162$.

[6] I.G. Richardson, Tobermorite/jennite- and tobermorite/calcium hydroxide-based models for the structure of C-S-H: applicability to hardened pastes of tricalcium silicate, beta-dicalcium silicate, Portland cement, and blends of Portland cement with blast-fumace slag, metakaolin, or silica fume, Cem. Concr. Res., 34 (2004) 1733-1777.

[7] K. Garbev, P. Stemmermann, L. Black, C. Breen, J. Yarwood, B. Gasharova, Structural features of C-S-H(I) and its carbonation in air - A Raman spectroscopic study. Part I: Fresh phases, J. Am. Ceram. Soc., 90 (2007) 900-907.

[8] P. Yu, R.J. Kirkpatrick, B. Poe, P.F. McMillan, X. Cong, Structure of calcium silicate hydrate (C-S-H): Near-, mid-, and far-infrared spectroscopy, J. Am. Ceram. Soc., 82 (1999) 742748.

[9] X. Cong, R.J. Kirkpatrick, ${ }^{29}$ Si MAS NMR study of the structure of calcium silicate hydrate, Adv. Cem. Based Mater., 3 (1996) 144-156.

[10] H.F.W. Taylor, Tobermorite, jennite, and cement gel, Z. Kristallogr., 202 41-50.

[11] C. Alonso, L. Fernandez, Dehydration and rehydration processes of cement paste exposed to high temperature environments, J. Mater. Sci., 39 (2004) 3015-3024. 
[12] P.A. Bonnaud, Q. Ji, K.J. Van Vliet, Effects of elevated temperature on the structure and properties of calcium-silicate-hydrate gels: the role of confined water, Soft Matter, 9 (2013) 6418-6429.

[13] J. Zhang, G.W. Scherer, Comparison of methods for arresting hydration of cement, Cem. Concr. Res., 41 (2011) 1024-1036.

[14] X.D. Cong, R.J. Kirkpatrick, Effects of the temperature and relative humidty on the structure of C-S-H gel Cem. Concr. Res., 25 (1995) 1237-1245.

[15] T. Mitsuda, H.F.W. Taylor, Normal and anomalous tobermorites, Mineral. Mag., 42 (1978) 229-235.

[16] C. Biagioni, E. Bonaccorsi, S. Merlino, D. Bersani, New data on the thermal behavior of 14 Å tobermorite, Cem. Concr. Res., 49 (2013) 48-54.

[17] M. Castellote, C. Alonso, C. Andrade, X. Turrillas, J. Campo, Composition and microstructural changes of cement pastes upon heating, as studied by neutron diffraction, Cem. Concr. Res., 34 (2004) 1633-1644.

[18] J. Neuefeind, M. Feygenson, J. Carruth, R. Hoffmann, K.K. Chipley, The Nanoscale Ordered MAterials Diffractometer NOMAD at the Spallation Neutron Source SNS, Nucl. Instrum. Meth. B, 287 (2012) 68-75.

[19] E. Lorch, Neutron diffraction by germania, silica and radiation-damaged silica glasses, J. Phys. C, 2 (1969) 229.

[20] A.K. Soper, C.J. Benmore, Quantum differences between heavy and light water, Phys. Rev. Lett., 101 (2008) 065502.

[21] P.A. Bonnaud, Q. Ji, B. Coasne, R.J.M. Pellenq, K.J. Van Vliet, Thermodynamics of water confined in porous calcium-silicate-hydrates, Langmuir, 28 (2012) 11422-11432. 
[22] J.J. Thomas, H.M. Jennings, A.J. Allen, Relationships between composition and density of tobermorite, jennite, and nanoscale $\mathrm{CaO}-\mathrm{SiO}_{2}-\mathrm{H}_{2} \mathrm{O}$, J. Phys. Chem. C, 114 (2010) 7594-7601. [23] C.L. Farrow, P. Juhas, J.W. Liu, D. Bryndin, E.S. Bozin, J. Bloch, T. Proffen, S.J.L. Billinge, PDFfit2 and PDFgui: computer programs for studying nanostructure in crystals, J. Phys. Condens. Matter, 19 (2007) 335219.

[24] S. Bouazizi, F. Hammami, S. Nasr, M.-C. Bellissent-Funel, Neutron scattering experiments on aqueous sodium chloride solutions and heavy water. Comparison to molecular dynamics and X-ray results, J. Mol. Struct., 892 (2008) 47-52.

[25] N.H. Brett, An X-ray investigation of the thermal decomposition of portlandite, Mineral. Mag., 37 (1969) 244-249.

[26] P.J. McDonald, V. Rodin, A. Valori, Characterisation of intra- and inter-C-S-H gel pore water in white cement based on an analysis of NMR signal amplitudes as a function of water content, Cem. Concr. Res., 40 (2010) 1656-1663.

[27] $\mathrm{H}$. Petch, The hydrogen positions in portlandite, $\mathrm{Ca}(\mathrm{OH})_{2}$, as indicated by the electron distribution, Acta Crystallogr, 14 (1961) 950-957.

[28] A.K. Soper, The radial distribution functions of water as derived from radiation total scattering experiments: Is there anything we can say for sure?, ISRN Phys. Chem., 2013 (2013) 279463.

[29] V.K. Peterson, B.A. Hunter, A. Ray, Tricalcium silicate $T_{1}$ and $T_{2}$ polymorphic investigations: Rietveld refinement at various temperatures using synchrotron powder diffraction, J. the Am. Ceram. Soc., 87 (2004) 1625-1634.

[30] D.K. Smith, A.J. Majumdar, F. Ordway, Re-examination of the polymorphism of dicalcium silicate, J. the Am. Ceram. Soc., 44 (1961) 405-411. 